\title{
LAS FUNCIONES DE LA RAZONABILIDAD EN EL DERECHO PRIVADO CHILENO
}

[The functions of the reasonableness in the chilean Private Law]

\author{
Lilian C. San Martín Neira* \\ Universidad Alberto Hurtado
}

\section{RESUMEN}

El presente trabajo presenta una visión panorámica de la acogida que ha tenido la noción de razonabilidad en el Derecho privado chileno. A través de la identificación del vocablo razonabilidad y sus derivados lingüísticos en los principales cuerpos normativos, así como en la doctrina y jurisprudencia nacionales, el texto describe los múltiples usos técnicos que se han hecho de la razonabilidad en el ámbito del Derecho privado nacional, concluyendo que ellos pueden ser agrupados principalmente en tres funciones: (i) la de cláusula general, esto es, como reenvío del legislador al criterio del juez; (ii) la de sinónimo de sensatez, indicando un parámetro o estándar de conducta; y (iii) la de instrumento para soslayar la incertidumbre propia de algunas instituciones civiles.

\section{Abstract}

This paper presents a panoramic view of the reception that has had the notion of reasonableness in Chilean Private Law. Through the identification of the word reasonableness and its linguistic derivatives in the main normative bodies, as well as in the national doctrine and Jurisprudence, the text describes the multiple technical uses that have been made of the reasonableness in the context of national Private Law, concluding that they can be grouped mainly in three functions: (i) as a general clause, that is, as a forwarding of the legislator to the judge's judgment; (ii) as a synonym of good sense, indicating a parameter or standard of conduct; and (iii) as a resource for elude the uncertainty of some civil institutions.

Recibido el 18 de mayo de 2018 y aprobado el 7 de enero de 2019

* Profesora de Derecho Civil, Universidad Alberto Hurtado. Dirección postal: Cienfuegos 41, Santiago. Correo electrónico: 1sanmar@uahurtado.cl. Este trabajo forma parte del proyecto FONDECYT No 1170686, del cual la autora es investigadora responsable. 
Palabras Clave

Derecho civil - Razonabilidad Derecho privado chileno - estándar de conducta - cláusula general.
KEYWORDS

Civil Law - Reasonableness - Chilean Private Law - standard of conduct - general clause.

\section{INTRODUCCIÓN}

Una de las características del llamado nuevo derecho de la contratación, encabezado por los principales instrumentos de unificación y armonización del Derecho Privado, a saber, la Convención de Viena Sobre Compraventa Internacional de Mercaderías (CISG), Principios UNIDROIT, Principios Europeos de Derecho de los Contratos (PECL), Borrador de Marco Común de Referencia (DCFR) y los recientes Principios Latinoamericanos de Derecho de los Contratos (PLDC), es la amplia presencia de la noción de razonabilidad ${ }^{1}$. El amplio empleo de la razonabilidad en estos ordenamientos salta a la vista del lector de los mismos y ha sido en más de una ocasión puesto en evidencia por la doctrina. En este sentido, señala PATTI que en el DCFR han sido contadas aproximadamente cuatrocientas utilizaciones de la razonabilidad en sus diversos derivados lingüísticos ${ }^{2}$. En lo que respecta a la Convención de Viena y a los principios UNIDROIT, se han contado cuarenta y siete y cincuenta y ocho referencias, respectivamente, al punto que se ha llegado a hablar de la "omnipresencia de lo razonable"3. Por su parte, en los PECL han sido contadas sesenta y cinco referencias ${ }^{4}$, incluyendo una definición de la misma, en su artículo 1:302.

${ }^{1}$ Se emplea de propósito la expresión neutra "noción de razonabilidad", pues, como ha puesto de manifiesto la doctrina que se ha ocupado de ella, la razonabilidad puede ser vista, entre otros, como un vocablo del lenguaje ordinario, como una cláusula general, como un estándar, como un juicio práctico de sentido común, como un concepto normativo-valorativo, como un término o concepto jurídico, o como un principio jurídico, sin que se trate de aspectos excluyentes entre sí. Vid. ZorzetTo, Silvia, Ragionevolezza, politica del diritto e semiotica giuridica. Considerazioni in margine al libro Ragionevolezza e autonomia negoziale, en Diritto \& Questioni Pubbliche 10 (2010), pp. 619 ss., disponible [en línea]: http://www.dirittoequestionipubbliche.org/, consultado 15 de ene. de 18.

${ }^{2}$ Patтi, Salvatore, Ragionevolezza e clausole generali (2a edición, Milán, Giuffrè, 2016), p. 26.

${ }^{3}$ Troiano, Stefano, La "ragionevolezza" nel diritto dei contratti (Padova, CEDAM, 2005), pp. 20 y 173.

${ }^{4}$ Troiano, Stefano, Ragionevolezza, en Enciclopedia del diritto. Annali VI (Milán, Giuffrè, 2013), p. 769. 
Un tanto inferior en número es la presencia de lo razonable en los Principios Latinoamericanos, en los cuales es posible contar siete referencias 5 . Dada esta multiplicidad de referencias, concordamos con Troiano en que en un trabajo de esta naturaleza no es el caso realizar el listado de todas ellas, pues "resultaría excesivo y cansaría demasiado al lector" 6 . Lo importante en este punto es destacar que el fenómeno consistente en la difusión del empleo de la razonabilidad en el Derecho privado, al igual que ha sucedido en otros países de tradición continental ${ }^{7}$, ha llegado al ordenamiento jurídico chileno, muy probablemente por la notoria influencia que los citados instrumentos y su doctrina están teniendo en el ámbito nacional, especialmente a nivel doctrinario, pero también legislativo y jurisprudencial ${ }^{8}$.

Frente a esta realidad, resulta oportuno preguntarse por el alcance que en el Derecho Privado chileno se ha dado a la noción en cuestión,

${ }^{5}$ Vid. el texto de los PLDC, disponible [en línea]: http://pldc.uexternado.edu.co/ PLDC-3xternado/wp-content/uploads/2018/01/PLDC-2017-Versio\%CC\%81nespan\%CC\%83ol.pdf (consultado 29 de agosto de 2018).

${ }^{6}$ Troiano, Stefano, cit. (n. 3), p. 20.

${ }^{7}$ En efecto, incluso con mayor énfasis, lo mismo ha acontecido en países tales como Argentina, España, Francia e Italia. V. gr. Vid. Troiano, Stefano, cit. (n. 3), passim; RIcci, Annarita, Il criterio della ragionevolezza nel diritto privato (Padova, CEDAM, 2007); Giorgini, Erika, Ragionevolezza e autonomia negoziale (Nápoles, Edizioni Scientifiche Italiane, 2010); Nicolau, Noemí Lidia, El principio de razonabilidad en el Derecho Privado en Revista de Derecho Privado 1 (2010), pp. 3-25; Troiano, Stefano, Ragionevolezza, cit. (n. 4), pp. 763-808; Perlingieri, Giovanni, Profili applicativi della ragionevolezza nel diritto civile (Nápoles, Edizioni Scientifiche Italiane, 2015); TomÁs Martínez, Gema, La influencia internacional en la creciente presencia del estándar de la razonabilidad en el derecho privado, en MurILlo Villar, Alfonso et alt., Homenaje al Profesor Armando Torrent (Madrid, Dikynson, 2016), pp. 1181-1197; РАтті, Salvatore, Ragionevolezza e clausole generali (2a edición, Milán, Giuffrè, 2016).

${ }^{8}$ Basten como ejemplos de esta influencia la preocupación de la doctrina por el interés del acreedor, que ha dado lugar a lo que se ha llamado el "sistema de remedios" frente al incumplimiento, entre los cuales puede optar el acreedor con mayor o menor libertad, incluyendo la pretensión indemnizatoria como remedio autónomo, y, como contrapartida a lo anterior, la identificación de una serie de deberes y cargas que pesan precisamente sobre el acreedor. En este sentido, $v$. gr. Vid. López Díaz, Patricia Verónica, La indemnización compensatoria por incumplimiento de los contratos bilaterales como remedio autónomo en el derecho civil chileno, en Revista chilena de derecho privado (2010), 15, pp. 65-113; Mejías Alonzo, Claudia, El incumplimiento resolutorio en el Código Civil (Santiago, AbeledoPerrot, 2011), passim; Prado López, Pamela, La colaboración del acreedor en los contratos civiles (Santiago, Thomson Reuters, 2015), passoim, Vidal O., Álvaro - Momberg U., Rodrigo (coordinadores), Cumplimiento especifico y ejecución forzada del contrato (Valparaíso, Ediciones Universidad de Valparaíso, 2018). 
evidenciando los diversos usos que de ella hacen los autores, el legislador y los tribunales. Precisamente a ello se aboca el presente trabajo, cuyo objetivo es identificar los usos o funciones que actualmente cumple la razonabilidad en el Derecho privado chileno, con la finalidad de invitar a la comunidad iusprivatista a reflexionar sobre esta noción en los diversos contextos en que es empleada, pues, de esta manera, se logrará dotarla de contenido y se evitará el peligro de dejarla como un enunciado vacío, que más bien se preste para la arbitrariedad. En efecto, uno de los peligros de los conceptos jurídicos indeterminados, como es la razonabilidad, es precisamente que, por su multiplicidad de concreciones posibles, finalmente se haga un empleo abusivo de los mismos, que termine por privarlos de verdadero contenido, lo que, a su vez, impide el control de las decisiones judiciales en que el concepto se concretice. Una de las formas de atajar dicho peligro es mediante la realización de grupos de casos, los cuales, una vez analizados en detalle, servirán para ilustrar el empleo correcto o equivocado del concepto, permitiendo así el control de las decisiones judiciales en que éste se concretice ${ }^{9}$. En este sentido, se ha señalado que, tratándose de la razonabilidad, el criterio más apropiado para realizar tal agrupación es "el relativo a la función que, en las diferentes disposiciones o en las aplicaciones concretas, es asignada a la razonabilidad" ${ }^{10}$. Bajo este entendido ha sido diseñado el presente trabajo, que se ocupa precisamente de las funciones que actualmente se asignan a la razonabilidad en el Derecho privado chileno, como un antecedente necesario para el análisis de las concreciones judiciales del mismo.

La base de este texto está dada por la identificación del vocablo razonabilidad y sus derivados lingüísticos en los principales cuerpos normativos del Derecho privado ${ }^{11}$, en la doctrina y en la jurisprudencia, para lo cual

9 Sustancialmente en este mismo sentido, Vid. BAZÁn L., José Luis - Madrid R., Raúl, Razonabilidad y racionalidad en el derecho, en Revista Chilena de Derecho (1991), 18-2, p. 180; Troiano, Stefano, cit. (n. 4), p. 771.

${ }^{10} \mathrm{Cfr}$. Troiano, Stefano, cit. (n. 4), p. 771. En conformidad con sus dichos, este autor ha identificado, para el derecho italiano, tres principales funciones de la razonabilidad, que sustancialmente coinciden con las que se le asigna en el Derecho nacional, a saber: a) Como un modelo que define el grado y el tipo de empeño debido o que es posible pretender de un sujeto al momento de realizar un determinado fin (en particular, en el cumplimiento de un deber o en la observancia de una carga); b) como fórmula de imputación de la responsabilidad por incumplimiento de un deber o la imputación de la inobservancia de una carga; $c$ ) como criterio de garantía o salvaguarda del equilibrio entre intereses que se contraponen en un contrato o en otra relación jurídica, que responde, por tanto, a una exigencia de moderación y equilibrio de los intereses en conflicto. Ídem, pp. 771 ss.

${ }^{11}$ Por considerar que son suficientemente ilustrativos, la búsqueda se ha limitado 
se ha recurrido principalmente, aunque no de forma exclusiva, a la búsqueda por palabras en diversas bases de datos jurídicas ${ }^{12}$. Esta búsqueda ha permitido constatar que en las distintas fuentes se hace un amplio uso del adjetivo razonable en expresiones tales como "resulta razonable", "parece razonable", "persona razonable", "motivos razonables", etc.; sin embargo, en la mayoría de los casos no resulta posible asignar a tales expresiones un contenido preciso, pues el recurso a la razonabilidad no aparece fundamentado, es decir, no resulta de un razonamiento al respecto, sino como una afirmación autoevidente, que no requiere explicaciones, lo mismo puede decirse del uso del adverbio razonablemente, del cual también se hace frecuente uso ${ }^{13}$.

Amén de lo anterior, el análisis de los textos que aluden a la razonabilidad ha permitido constatar que en nuestro ordenamiento existe también un uso técnico de la misma, el cual, con diversos matices, puede dividirse principalmente en tres funciones: (i) la función de establecer un parámetro de tiempo, cantidad o idoneidad en casos en que una misma norma está llamada a regir una serie heterogénea de hipótesis fácticas; (ii) la de sinónimo de sensatez, en este sentido, se usa el adjetivo razo nable para aludir a la conducta y/o decisiones que una persona sensata adoptaría

al Código Civil, Código de Comercio y a la Ley de Protección a los Derechos de los Consumidores, Ley 19.496.

${ }^{12}$ Las bases de datos utilizadas para estos efectos han sido: googlescholar; scielo; Vlex y Thomson Reuters, las que han permitido realizar un análisis tanto de la doctrina, como de la jurisprudencia nacional contenidas en ellas. La búsqueda jurisprudencial no fue deliberadamente delimitada por espacio temporal, sin embargo, es posible advertir que todas las sentencias citadas son posteriores al año 2000 y la mayor parte se concentran en los últimos cinco ańos.

${ }^{13}$ Una posible explicación para este estado de cosas es el hecho de que no existen en nuestro medio estudios acerca de la razonabilidad y sus implicancias en Derecho privado, distinto es lo que ocurre en otras áreas del Derecho, tales como el Derecho penal y público, en que la doctrina sí ha prestado mayor atención al punto. Vid. Martínez, José Ignacio - ZúÑIga Urbina, Francisco, El principio de razonabilidad en la jurisprudencia del Tribunal Constitucional, en Estudios Constitucionales (2011), 1, pp. 199-226; Carnevali Rodríguez, Raúl - Castillo Val, Ignacio, El estándar de convicción de la duda razonable en el proceso penal chileno, en particular la relevancia del voto disidente, en Ius et Praxis (2011), 2, pp. 77-118; Carrasco Quiroga, Edesio, Razonabilidad y proporcionalidad: criterios para la determinación de la consulta indígena en proyectos de inversión en el marco del convenio No 169 de la OIT, en Revista Chilena de Derecho 40 (2013), 1, pp. 299-314; Finsterbusch Romero, Christian, La extensión de los ajustes razonables en el derecho de las personas en situación de discapacidad de acuerdo al enfoque social de derechos humanos, en Ius et Praxis 22 (2016), 2, pp. 227-25; Huepe Ártigas, Fabián, Discrecionalidad administrativa y razonabilidad (Santiago, Thomson Reuters, 2018), passim. 
en caso de encontrarse en la posición del sujeto cuestionado; y (iii) la de sinónimo de plausible, en este caso, a través del adjetivo razonable, se recurre a la razonabilidad para soslayar la incerteza que necesariamente conllevan algunas instituciones propias del derecho privado, tales como la indemnización del lucro cesante, el nexo de causalidad material en algunos casos y el llamado daño contingente, asociado a la responsabilidad civil preventiva. En lo que sigue daremos cuenta de estas afirmaciones.

\section{LA RAZONABILIDAD COMO PARÁMETRO DE TIEMPO, CANTIDAD O IDONEIDAD}

\section{Premisa: la razonabilidad como cláusula general y concepto jurídico indeterminado}

En la técnica legislativa, se ha reconocido desde antiguo la necesidad de recurrir a ciertos enunciados abiertos, que dejan entregada al juez la tarea de concretarlos caso a caso, adaptándolos a las circunstancias de la cuestión sometida a su conocimiento, tal es el caso, por ejemplo, de la 'buena fe objetiva' y de la 'culpa', pues ambos conceptos requieren de la valoración de las circunstancias del caso concreto para determinar si se han respetado las exigencias de la buena fe o bien se ha incurrido en culpa, respectivamen$\mathrm{te}^{14}$. Lo mismo puede decirse de las normas que aluden al 'orden público' o a las 'buenas costumbres', pues también ellas dejan entregada al juez la tarea de concretizar su aplicación conforme a las circunstancias del caso. Se trata de normas dotadas de elasticidad, en la medida que contienen la alusión a un concepto jurídico indeterminado, que debe ser concretizado por el juez en los fundamentos de su decisión ${ }^{15}$. "Las expresiones 'concepto jurídico indeterminado' y 'cláusula general' aluden, por tanto, en una primera aproximación, a una peculiar técnica legislativa, consistente en acudir a normas que, en lugar de regular hipótesis individualizadas de manera analítica, o bien prescribir conductas precisas, reenvían a categorías

\footnotetext{
${ }^{14}$ Ampliamente sobre este particular, Vid. BARCEllona, Mario, Clausole generali e giustizia contrattuale. Equità e buona fede tra Codice civile e diritto europeo (Turín, Giappichelli, 2006), passim.

${ }^{15} \mathrm{Si}$ bien cabe reconocer que la relación entre "cláusula general" y "concepto jurídico indeterminado", no es del todo nítida, ni pacífica en doctrina. En esta sede se asume la tesis tradicional según la cual la cláusula general alude a la norma jurídica que requiere ser integrada con el criterio judicial, mientras que el concepto jurídico indeterminado alude a una característica del concepto mismo. Sobre este particular, vid Patti, Salvatore, cit. (n. 2) p. 65. Para un análisis más extenso de la relación entre ambos conceptos, Vid. Troiano, Stefano, cit. (n. 3), pp. 48 ss.; Fabiani, Ernesto, Clausola generale, en Enciclopedia del diritto. Annali V (Milán, Giuffrè, 2012), pp. 183 ss.
} 
o grupos, más o menos extensos, de hechos y de conductas, a los cuales conectan valoraciones jurídicas" 16 .

Como se advirtió en la introducción, el llamado nuevo Derecho de la contratación contiene numerosas normas que, con carácter de cláusula general, acuden precisamente a la razonabilidad para dotar al juez del poder de decidir la cuestión conforme a lo que resulte razonable, pero lo interesante en este punto es que también en la legislación nacional es posible encontrar este tipo de normas, lo que es particularmente destacable atendido que en gran parte se trata de normas que provienen de la redacción original del Código Civil y que también se encuentran en el Código de Comercio. En efecto, probablemente por la influencia que tuvo en el pensamiento de Bello el pragmatismo británico ${ }^{17}$, el codificador nacional recurrió a la razonabilidad como una herramienta para dejar al criterio del juez la adopción de la solución que mejor se avenga al caso concreto, allí donde no parece adecuado el establecimiento de una regla precisa, formulada $a$ priori, pues la variedad de casos regidos por el mismo enunciado normativo determinaría en algunas ocasiones situaciones de injusticia. Así, mediante el recurso a la razonabilidad, se otorga al juez el poder para fijar una regla particular y adoptar la decisión sobre la base de las circunstancias propias del caso sometido a su consideración. En tal sentido, el Código Civil emplea las expresiones "plazo razonable" y "gastos razonables"18.

\section{La razonabilidad como parámetro para establecer un plazo, la cantidad} o idoneidad exigidos por una norma

Lo característico de las normas legales aludidas en el párrafo anterior, es que todas ellas utilizan la razonabilidad para dar el juez un parámetro para concretizar un plazo, un gasto o bien la idoneidad de una determinada acción. Así, se recurre a la expresión "plazo razonable” cuando la fijación de un período preestablecido de tiempo resultaría arbitraria, pues una misma disposición engloba casos en que el plazo aceptable son dos o tres días, así como otros en que pueden ser seis meses o más. En tal sentido, a modo

${ }^{16}$ Cfr. Troiano, Stefano, cit. (n. 3), p. 49. (traducción libre).

${ }^{17}$ Los veinte años transcurridos en Inglaterra desde luego influenciaron el pensamiento jurídico de Bello, quien se hizo particularmente adepto a la doctrina del utilitarismo de Jeremy Bentham. Sobre los ańos transcurridos en Londres y el contacto de Bello la obra de Bentham, Vid. De Ávila Martel, Alamiro, La filosofía jurídica de Andrés Bello, en AA.VV., Congreso Internacional Andrés Bello y el Derecho (Santiago, Editorial Jurídica de Chile, 1982), pp. 47 ss.; Jaksic, Ivan, Andrés Bello, la pasión por el orden (Santiago, Editorial Universitaria, 2001), pp. 59 ss.

${ }^{18}$ Para todas, Vid. CCCh. artículos 1276, 1935, 1977, 2010, 2158, 2125, 2167 , 2183, y 2361. 
de ejemplo, pueden citarse los artículos 2125, 2167 y 2183 del Código Civil. El primero, relativo al plazo razonable que tiene una persona que se encarga de negocios ajenos para manifestar si acepta o rechaza el encargo de una persona ausente; el segundo, relativo al plazo razonable en que se hará efectiva la renuncia del mandatario, con el fin de que el mandante se haga cargo de sus negocios; $y$, el tercero, relativo al plazo razonable que el comodatario, que advierte que el comodato es una cosa hurtada o robada, debe darle al dueño para que la reclame.

La noción de plazo razonable es también empleada en otros cuerpos normativos de Derecho privado, en especial, cabe destacar el Código de Comercio y la Ley Protección de los Derechos de los Consumidores. Al igual que en el Código Civil, se trata de normas destinadas a regir una amplia gama de situaciones de hecho y, por lo mismo, el establecimiento de un plazo predeterminado no parece una solución legislativa adecuada ${ }^{19}$.

Por su parte, la expresión "gastos razonables" es empleada para resolver casos en que la cuantía de gastos permitida dependerá de las circunstancias del caso. Así, por ejemplo, según el artículo 1935 del Código Civil, el arrendador que se vea en la necesidad de realizar reparaciones no locativas tiene derecho al reembolso de los "gastos razonables", de esta manera, lo que el arrendatario puede gastar en la realización de tales reparaciones dependerá, por ejemplo, del tipo de casa y de los materiales con esté construida. Otro ejemplo de este empleo de la razonabilidad está dado por el artículo 2158 del mismo Código Civil, en virtud de esta norma el mandante queda obligado para con el mandatario a "reembolsarle los gastos razonables causados por la ejecución del mandato", ciertamente estos gastos dependerán, entre otras cosas, de la naturaleza del mandato y de las condiciones económicas de las partes. La expresión gastos razonables también puede observarse en el Código de Comercio, que la contempla a propósito de las obligaciones de reembolso que tiene el asegurador para con el asegurado ${ }^{20}$.

Amén de lo anterior, en el Código de Comercio es posible encontrar expresiones tales como "medidas razonables"21, "diligencia razonable" 22 , "medios razonables"23, "facilidades razonables"24 todas las cuales constituyen un reenvío al caso concreto entregando al juez la posibilidad de juzgar la idoneidad de la medidas, medios, diligencia y facilidades desplegadas

${ }^{19}$ Vid. Código de Comercio, artículos 244, 571, 985 y 1046; Ley 19.496, artículo 17 B letra b).

${ }^{20}$ Vid. Código de Comercio, artículo 524 № 8.

${ }^{21}$ Vid. Código de Comercio, artículos 984, 987, 990 y 1132.

${ }^{22}$ Vid. Código de Comercio, artículos 940, 950 y 1051.

${ }^{23}$ Vid. Código de Comercio, artículos 1017 y 1018.

${ }^{24}$ Vid. Código de Comercio, artículo 1028. 
por el destinatario de la norma y, a su vez, de definir aquellos que resulten idóneos conforme a las circunstancias del caso concreto.

En síntesis, mediante el empleo de expresiones como plazo razonable, gastos razonables y otras semejantes, el codificador estuvo en grado de dictar una disposición válida para todas las situaciones encuadrables en el supuesto fáctico de la norma, dejando al juez la tarea de concretarla conforme a las circunstancias del caso sometido a su decisión. Lo característico de esta función de la noción de razonabilidad en el Derecho Privado chileno es que, a diferencia de las demás funciones, que tienen más bien reconocimiento doctrinario y jurisprudencial, ésta ha sido establecida por el propio legislador, con el fin de evitar los problemas asociados a la rigidez de las normas legales ${ }^{25}$.

\section{LA RAZONABILIDAD COMO SINÓNIMO DE SENSATEZ}

Esta parece ser la fórmula mayormente empleada de la noción de razonabilidad, tanto en la doctrina como en la jurisprudencia nacional; en efecto, son frecuentes tanto las citas doctrinarias como jurisprudenciales a lo razonable, para aludir a lo adecuado o sensato en las condiciones analizadas ${ }^{26}$. La mayor parte de las veces se trata de expresiones formuladas al pasar, sin que pueda atribuírsele alguna connotación más precisa, así como tampoco alguna consecuencia práctica particularmente relevante; sin embargo, en otras oportunidades la expresión cobra un sentido importante, pues, como se verá en seguida, es empleada como criterio decisorio de la cuestión controvertida.

El uso que en este caso se hace de la razonabilidad no es del todo uniforme, por lo cual, sobre la base las utilizaciones específicas del concepto, es posible realizar algunas subdistinciones, a saber: (i) la razonabilidad como estándar de conducta; (ii) la razonabilidad como elemento para delimitar los contornos de la confianza legítima; y (iii) la razonabilidad para modelar

${ }^{25}$ En este sentido se destaca que el tema de las cláusulas generales es un problema propio de los ordenamientos codificados, mientras que es prácticamente desconocido en los sistemas de corte casuístico. En efecto, es sólo en los sistemas en que la ley es la fuente primaria de producción del derecho y en que la magistratura está relegada, en línea de máxima, a la aplicación de la ley, que surge el problema de que la rigidez de la norma impida dar cuenta de las particularidades del caso concreto, creando situaciones de injusticia. Vid. Troiano, Stefano, cit. (n. 3), pp. 65 ss.

${ }^{26}$ También en la legislación es posible ver algunas expresiones que conllevan este sentido. $V . g r$. en el Código de Comercio es posible ver expresiones tales como "abandono razonable", artículo 512 y "motivos razonables" artículo 1017. 
las exigencias de la buena fe. A continuación, se presenta un breve análisis de cada uno de tales usos.

\section{La razonabilidad como estándar de conducta, paulatino reemplazo de} la expresión "buen padre de familia"

Como es sabido, una de las figuras clásicas de nuestra tradición jurídica es la del buen padre de familia, el cual indica un modelo de comportamiento ideal, con el cual debe ser comparado el sujeto concreto y, de esta forma, establecer, por ejemplo, si ha incurrido en culpa a la hora de provocar un accidente, o bien, de incumplir un contrato; sin embargo, en la actualidad es frecuente encontrar que dicho modelo es descrito empleando la expresión persona u hombre razonable, ya sea de forma exclusiva ${ }^{27}$, o bien acostándola a la tradicional fórmula del buen padre de familia, con el fin de aclarar su significado ${ }^{28}$.

A nuestro juicio, la razón de este cambio en el lenguaje obedece a dos series de razones: por un lado, la expresión persona razonable es más auto-explicativa, mientras que hablar de buen padre de familia requiere una explicación adicional, especialmente cuando el discurso va dirigido a personas que no son especialistas y, por otro, la expresión buen padre de familia aparece anacrónica, ella es fruto de la sociedad patriarcal en que fue forjada y no se condice con una sociedad que predica la igualdad de géneros, esto último explica también la preferencia mayoritaria por la expresión persona, en lugar de hombre razonable ${ }^{29}$. De esta manera, el

${ }^{27}$ V. gr. Pizarro Wilson, Carlos, Daños en la construcción, fuerza mayor y terremotos, en Revista de Derecho de la Pontificia Universidad Católica de Valparaíso 34 (2010), p. 165; BANFI DEL Río, Cristián, Por una reparación integral del daño extracontractual limitada a los hechos dolosos o gravemente negligentes, en Ius et Praxis 18 (2012), 2, p. 16 ss.; Corte Suprema, 13 de julio de 2015, Rol No 26201-2014. Cabe señalar que otros autores han preferido la expresión "hombre prudente" para indicar al mismo modelo de conducta; en este sentido Vid. Corral Talciani, Hernán, Lecciones de responsabilidad extracontractual ( $2^{\text {a }}$ edición, Santiago, Thomson Reuters, 2013), pp. 206 ss. El estándar de persona razonable es empleado también cuando se trata de establecer el parámetro de conducta en la culpa de la víctima, Pizarro W., Carlos - Bahamondes O., Claudia, La exposición de la víctima al daño: desde la culpabilidad a la causalidad, en Revista de Derecho de la Pontificia Universidad Católica de Valparaíso 39 (2012), p. 46.

${ }^{28} \mathrm{~V}$. gr. Barros Bourie, Enrique, Tratado de responsabilidad extracontractual (Santiago, Editorial Jurídica de Chile, 2006), p. 81; TAPIA R., Mauricio, Caso fortuito en el Derecho chileno (Santiago, LegalPublishing, 2013), p. 22; Corte de Apelaciones de San Miguel, 19 de enero de 2015, Rol No 434-2014.

${ }^{29}$ Nótese que este análisis no es válido solamente para la realidad nacional, el mismo llevó a que en Francia se modificara el Code Civil precisamente con el objetivo de 
cambio de nomenclatura parece ser más bien formal, siendo así, resulta dable sostener que la expresión persona razonable es sustancialmente equivalente a la de buen padre de familia. Así parece entenderlo también la jurisprudencia, que hace sinónimas ambas nociones. En tal sentido pueden verse las expresas afirmaciones de la Corte de Santiago, la cual ha señalado: "que, con base en lo dispuesto en el artículo 44 del Código Civil, es posible establecer que el estándar de conducta exigible en materia de responsabilidad extracontractual es el de la culpa leve, que corresponde al que sigue una persona diligente, que emplea un cuidado ordinario o mediano. En nuestro Derecho, el modelo a aplicar es el del "buen padre de familia", figura que alude a la prudencia con que se maneja una persona razonable y diligente. La forma de apreciar la culpa en nuestro sistema, entonces, es de carácter abstracto, ya que se basa en la consideración de un estándar objetivo (persona razonable y prudente), con el cual ha de compararse la conducta realizada por aquel a quien se le imputa responsabilidad en un caso específico, sin perjuicio que su determinación se efectúe en concreto"30.

Lo relevante de esta última constatación es que, a pesar del cambio de nomenclatura, el legado de la tradición romana anclada a la expresión buen padre de familia puede ser utilizado para dotar de contenido concreto a la expresión persona razonable. Con todo, aunque deberá quedar pendiente por exceder los propósitos de este trabajo, que sólo persigue identificar los casos en que se recurre a la razonabilidad en el Derecho privado chileno, valdría la pena preguntarse qué hay en el cambio de nomenclatura más allá de los aspectos lingüísticos, pues no deja de ser cierto el hecho de que la expresión buen padre de familia arranca de la tradición romanista, mientras que la de persona razonable proviene de la tradición anglosajona y eventualmente ambos modelos podrían no ser necesariamente coincidentes ${ }^{31}$.

sustituir la expresión buen padre de familia por el de persona razonable. Sobre este cambio y sus implicancias prácticas, Vid. Tomás MarTínez, Gema, La sustitución del "buen padre de familia" por el estándar de la "persona razonable": reforma en Francia y valoración de su alcance, en Revista de Derecho Civil 2 (2015), 1, pp. 57-103. Disponible [en línea]: http://www.nreg.es/ojs/index.php/RDC/issue/view/18/showToc (consultado el 15 de enero de 2018).

${ }^{30}$ Cfr. Corte de Apelaciones de Santiago, 31 de diciembre de 2009, Rol No 29752008. En sentido semejante, Corte Suprema, 12 de junio de 2013, Rol No 24482010 .

${ }^{31}$ A propósito de la reforma francesa, la misma pregunta se ha formulado Tomás Martínez, quien concluye que "decir que el reemplazo es meramente lingüístico sólo es verdad en parte. Por un lado, el nuevo estándar es más correcto formalmente en términos de género, pero no garantiza una aplicación neutral en términos de género. Y por otro, tampoco es más comprensible en el sentido de que sea más fácil de interpretar, en ausencia de un automatismo objetivo en su aplicación. Para dar jus- 
Por otro lado, cabe señalar que lo razonable como estándar de conducta deseable no se predica sólo de las personas naturales, sino que también se ha utilizado como parámetro para evaluar el funcionamiento de las instituciones a la hora de calificar la responsabilidad extracontractual en que pueden incurrir ${ }^{32}$. Así ha ocurrido con la responsabilidad civil por falta de servicio. En este caso, la doctrina sostiene que la responsabilidad de la administración "es posible que sea evaluada desde la perspectiva del estándar de cumplimiento de la actividad administrativa. Lo que sucede es que estos estándares, por regla general, no están determinados explícitamente, es obligación del juez construirlos con criterio de razonabilidad"33. En consonancia con esta doctrina, en la jurisprudencia relativa a la responsabilidad por falta de servicio es posible leer expresiones tales como "estándar de servicio medio y razonable" 34 , "estándar razonable del servicio"35, "estándar legal o razonable de cumplimiento de la función pública"36 y "estándar razonable de funcionamiento del servicio" 37 , todas las cuales dan cuenta de la conducta esperada de la organización administrativa demandada.

En otro orden de cosas, pero siempre con referencia a un estándar de conducta, la razonabilidad es empleada como criterio para describir la actitud que debe adoptar el acreedor frente al incumplimiento ${ }^{38} \mathrm{y}$, más en general, la víctima frente a una situación que genera daño. Expresamente en este sentido afirma Vidal que "así como del deudor existe una expectativa razonable de conducta, el mismo imperativo pesa sobre el acreedor, a pesar

tificación de estas dos afirmaciones es necesario conocer el estándar de la «reasonable person" porque si bien es relevante la eliminación del ordenamiento civil francés del buen padre de familia, lo es más aún la incorporación del estándar que le reemplaza”. Cfr. Tomás Martínez, Gema, cit.. (n. 29), p. 66. Algunas consideraciones sobre la diferencias que corren entre la razonabilidad en los ordenamientos codificados y el concepto de reazonableness en los sistemas de Common Law, pueden verse en PAтTi, Salvatore, cit. (n. 2), pp. 21 ss.

${ }^{32}$ Vid. Corte Suprema, 29 de octubre de 2013, Rol No 3-2013.

${ }^{33}$ Cfr. Cordero Vega, Luis, La responsabilidad por falta de servicio y la jurisprudencia de la Corte Suprema, en Letelier Wartenberg, Raúl (coordinador), La falta de servicio (Santiago, Thomson Reuters, 2012), p. 89.

${ }^{34}$ Vid. Corte Suprema, 8 de abril de 2013, Rol No 4233-2012.

${ }^{35}$ Ídem.

${ }^{36}$ Vid. Corte Suprema, 12 de noviembre de 2012, Rol No 6014-2010; Corte Suprema, 6 de junio de 2017, Rol No 87889-2016.

${ }^{37}$ Ídem.

${ }^{38}$ En este sentido, Vidal Olivares, Álvaro, La gestión razonable de los efectos del incumplimiento en la compraventa internacional, en Revista de Derecho (Valdivia) 18 (2005), 2, pp.55-85; Pizarro Wilson, Carlos, Notas límites a la pretensión de cumplimiento del contrato, en Revista de Derecho Universidad Católica del Norte (2014), 1, pp. 203-219; 
de ser víctima del incumplimiento"39. Como consecuencia de esta exigencia, se dice, por ejemplo, que el acreedor debe adoptar medidas razonables conducentes a evitar o mitigar los daños derivados del incumplimiento ${ }^{40}$, o bien que debe existir una proporcionalidad entre los incumplimientos para poder alegar la excepción de contrato no cumplido ${ }^{41}$. En estrecha relación con lo recién visto, se ha sostenido que "si el deudor ofrece, o ha ofrecido, subsanar la prestación, de manera razonable, no sería posible exigir, al menos, la resolución del contrato", pues comportaría un abuso de dicho remedio contractual ${ }^{42}$. En síntesis, la razonabilidad como sinónimo de sensatez y, en último término, de rectitud es empleada tanto para describir la conducta del deudor como del acreedor.

2. La razonabilidad como criterio para determinar la legitimidad de la confianza o de las expectativas que una persona puso en determinadas circunstancias

En este sentido, la expresión es utilizada en diversos ámbitos del De-

${ }^{39}$ Cfr. Vidal Olivares, Álvaro, La pretensión de cumplimiento especifico de las obligaciones no dinerarias y los costes excesivos para el deudor como limite a su ejercicio, en Vidal O., Álvaro - Momberg U., Rodrigo (editores), Cumplimiento especifico y ejecución forzada del contrato (Valparaíso, Ediciones Universidad de Valparaíso, 2018), p. 192.

${ }^{40}$ VIdal Olivares, Álvaro, La carga de mitigar las pérdidas del acreedor y su incidencia en el sistema de remedios por incumplimiento, en GuZMÁn BRITO, Alejandro (editor), Estudios de Derecho Civil III (Santiago, LegalPublishing, 2008), pp. 429 ss.; Gandarillas Serani, Cristián, Algunas consideraciones acerca del deber de mitigación o minimización del daño frente al incumplimiento contractual, en Pizarro WiLson, Carlos (coordinador), Estudios de Derecho Civil IV (Santiago, LegalPublishing 2009), pp. 435 ss.; SAN Martín NeIra, Lilian C., El criterio de "lo razonable". Una herramienta para delimitar la carga del perjudicado de evitar o mitigar el daño, en Derecho y Justicia 1 (2011), pp. 43 ss., disponible [en línea]: http://www.derecho-ucsh.cl/ categoria/revista/ (consultado 17 de enero de 2018); SAN Martín Neira, Lilian C., La carga del perjudicado de evitar o mitigar el daño (Bogotá, Universidad Externado de Colombia, 2012); Pizarro Wilson, Carlos, Contra la fatalidad del perjuicio. A propósito del deber de mitigar el daño, en Revista de Derecho de la Pontificia Universidad Católica de Valparaíso 41 (2013), pp. 69 ss.

${ }^{41}$ Vid. Mejías Alonzo, Claudia, La excepción de contrato no cumplido, un análisis de su aplicación en la jurisprudencia nacional reciente y en la doctrina, en Revista de Derecho Universidad Católica del Norte (2014), 1, p. 135. En jurisprudencia, Vid. Corte Suprema, 26 de julio de 2017, Rol No 65396-2016.

${ }^{42}$ Cfr. Contardo González, Juan Ignacio, El derecho del deudor a la subsanación o corrección del cumplimiento no conforme [right to cure]. Acercamiento desde los instrumentos de derecho contractual uniforme hacia el derecho chileno de contratos, en Ius et Praxis 23 (2017), 1, p. 184. 
recho Privado, todos los cuales tienen como sustrato común la protección de la confianza legítima:

a) Se emplea la razonabilidad para determinar una eventual responsabilidad precontractual, a raíz de la lesión a la confianza legítima creada en la contraparte $^{43}$, se sostiene que existe confianza legítima cuando una persona razonable, sensata, puesta en las mismas circunstancias de la víctima que demanda la indemnización, habría confiado en que las negociaciones llevarían a la conclusión del contrato. En este sentido, en sentencia de 19 de julio de 2017, la Corte de apelaciones de Santiago señaló expresamente que la responsabilidad precontractual exige "el quebrantamiento de la confianza razonable creada en la contraparte" 44 .

b) Se emplea la idea de razonabilidad para calificar la excusabilidad o inexcusabilidad del error. En este sentido se sostiene que el error es excusable cuando una persona razonable, sensata, habría tomado por verdadera la información con que contaba y, por ende, habría incurrido en el mismo error en que incurrió el errans. En este sentido, a propósito de un caso resuelto por la Corte Suprema, afirma De la Maza: "el de deber de investigar [del errans] comienza allí donde concluye la confianza razo-

${ }^{43}$ Tanto la doctrina como la jurisprudencia están contestes en que lo que desencadena la responsabilidad precontractual no es el hecho de haber interrumpido las negociaciones, sino la lesión a la confianza legítima creada en la contraparte de que el contrato se celebraría. $V$. gr. Corte Suprema, 29 de diciembre de 2011, Rol No 1872-2010, la cual afirma: "Que entre los deberes precontractuales de quienes participan de las tratativas preliminares está el deber de lealtad, que exige llevar adelante las negociaciones de buena fe, esto es, con el propósito efectivo de celebrar un contrato; y que también suponen deberes de cuidado al terminar la negociación, cuando se ha creado en la contraparte la confianza de que se celebrará el contrato". En doctrina, Vid. BARRos, Enrique, cit. (n. 28), p. 1008; Celedón Förster, Rosario - Silberman VeszpreMI, Patricia, Responsabilidad precontractual por ruptura de negociaciones contractuales (Santiago, Editorial Jurídica de Chile, 2010), pp. 118 ss.; López Díaz, Patricia, Los supuestos y el alcance de la indemnización de daños como medio de tutela precontractual en el Código Civil chileno y su eventual confluencia con la indemnización por incumplimiento contractual, en Revista Ius et Praxis 24 (2018), 1, p. 252.

${ }^{44}$ Cfr. Corte Apelaciones de Santiago, 19 de julio de 2019, Rol No 12655-2016. En sentido similar, Corte Suprema, 5 de marzo de 2015, Rol No 30469-2014. De último en este mismo sentido se ha señalado que "la responsabilidad precontractual por ruptura injustificada de las negociaciones preliminares no pretende, entonces, exigir que quienes inician conversaciones preliminares, elaboran proyectos, borradores o minutas, negocian objetivos y ponderan posibilidades, resulten obligados a celebrar un contrato, sino alcanzar el debido equilibrio entre la libertad contractual, que no puede ejercerse de forma abusiva, y la buena fe objetiva, que impide el retiro arbitrario de quien ha generado la confianza razonable en torno a la conclusión del contrato proyectado". Cfr. López, Patricia, cit. (n. 43), p. 252. 
nable y parece razonable confirmar en que la información que suministran los documentos de un vehículo se compadece con la realidad. El error, entonces, fue excusable" ${ }^{45}$.

c) Un tercer caso en este subgrupo está dado por la protección de la apariencia. Así, por ejemplo, se ha dicho que el pago hecho al acreedor aparente (en nuestro medio llamado "poseedor del crédito") es válido cuando el deudor confió razonablemente en que quien se presentaba a recibir el pago era el verdadero acreedor o bien su legítimo representante, es decir, realizó las diligencias que una persona sensata habría realizado para acertarse de la veracidad de lo afirmado por el tercero ${ }^{46}$.

d) Un razonamiento semejante al anterior se hace a propósito de la doctrina de los actos propios, en que se para determinar la legitimidad de la confianza depositada en la conducta del tercero se afirma que esta confianza ha de aparecer razonable $e^{47}$.

e) En el sentido que venimos exponiendo, también se ha empleado la razonabilidad para determinar la noción de vició en la construcción contenido en el artículo 2003 del Código Civil, al respecto se ha señalado que "este concepto puede entenderse, siguiendo los razonamientos empleados a propósito de los productos defectuosos, cuando no responde a las expectativas legítimas de calidad y de seguridad de un hombre medio y razonable. Aquí lo relevante es la apreciación de los defectos siguiendo un patrón del hombre medio y razonable. El análisis considera la opinión de ese modelo para distinguir si concurre o no el defecto" ${ }^{48}$.

f) Finalmente, siguiendo la doctrina anglosajona, especialmente de estadounidense ${ }^{49}$, se ha propuesto acoger la doctrina de las expectativas razonables para otorgar protección al contratante débil, específicamente al consumidor; en este caso, se abre la posibilidad de revisar el contrato

${ }^{45}$ Cfr. De la Maza Gazmuri, Íñigo, Comentarios de jurisprudencia. Contratos especiales", en Revista Chilena de Derecho Privado 15 (2010), p. 221. En sentido semejante, De la Maza Gazmuri, Íñigo, La distribución del riesgo y la buena fe. A propósito del error, el dolo y los deberes precontractuales de información, en Revista de Derecho Pontificia Universidad Católica de Valparaíso 37 (2011), p. 131.

${ }^{46}$ [Suprimido].

${ }^{47}$ Vid. EKdahl Escobar, María Fernanda, La doctrina de los actos propios: el deber jurídico de no contrariar conductas propias pasadas (Santiago, Editorial Jurídica de Chile, 1989), pp. 36 ss.; Abusleme Salah, María Agnes, Las doctrinas de los actos propios y de la protección a la apariencia: una mirada comparativa, en Revista del Magister y Doctorado en Derecho de la Universidad de Chile 2 (2008), pp. 199 ss.

${ }^{48}$ Pizarro, Carlos, cit. (n. 27), p. 165.

${ }^{49}$ Un resumen de esta doctrina puede verse en De la Maza Gazmuri, Ínigo, Contratos por adhesión. Una mirada al caso estadounidense, en Revista Chilena de Derecho Privado 5 (2005), pp. 9-41. 
cuando el contratante débil demuestre una inconsistencia entre lo que razonablemente podía esperarse del contrato celebrado y aquello que efectivamente se celebró, producto de su aceptación formal del mismo ${ }^{50}$.

\section{La razonabilidad como criterio para modelar las exigencias de la buena fe}

Como es sabido, una de las grandes diferencias entre el Common Law y la tradición romanista es el espacio reservado a la buena fe: mientras que la tradición romanista dedica una gran atención a la buena fe, imponiendo una serie de deberes derivados de ella, en el Common Law la buena fe resulta ser un concepto más bien ajeno y en su lugar se prefiere el recurso a la reasonable person ${ }^{51}$. Así las cosas, la recepción de la noción de razonabilidad en los ordenamientos continentales conlleva necesariamente una intrínseca relación con la cláusula general buena $\mathrm{fe}^{52}$. Sin perjuicio de que

${ }^{50}$ Vid. Pinochet Olave, Ruperto, La protección del contratante débil: doctrina de las expectativas razonables, en Gaceta Jurídica 297 (2005), pp. 18 ss., consultado en Thomson Reuters, cita on line: CL/DOC/3549/2012. En particular, según este autor, esta doctrina es plenamente coincidente con las exigencias de la buena fe contractual, contempladas en el artículo 1546, "por lo que la aplicación en Chile de las expectativas razonables no requiere a priori, como pudiere pensarse, de una modificación legal, sino que a nuestro entender, se necesita recurrir nada más que a la interpretación genuina de la norma”. Ídem. En jurisprudencia, aunque en el voto disidente, esta doctrina ha sido recientemente acogida a propósito de un fallo relativo a un "reconocimiento de deuda y compromiso de pago", en que los suscriptores asumieron que al suscribir dicho acuerdo su deuda sería eliminada de los registros comerciales de morosidad, cuestión que no era así y que el acreedor nunca tuvo intención de realizar. Vid. Corte Suprema, 21 de diciembre de 2017, Rol № 621732016, Un comentario a esta sentencia, haciendo hincapié en la pregunta ¿cómo han de establecerse las expectativas razonables?, puede verse en De la MAZA Gazmuri, Ínigo, Información y expectativas razonables, en El Mercurio Legal, viernes 05 de enero de 2018, disponible [en línea]: http://www.elmercurio.com/Legal/Noticias/AnalisisJuridico/2018/01/05/Informacion-y-expectativas-razonables.aspx (consultado 15 de enero de 2018).

${ }^{51}$ Una breve reseña de este panorama puede verse en Segura Riveiro, Francisco, Buena fe, un aspecto de tensión entre los sistemas jurídicos, en Departamento De Derecho Privado Universidad de Concepción (coordinador), Estudios de Derecho Civil V (Santiago, Thomson Reuters, 2010), pp. 499 ss.

${ }^{52}$ Una particular atención a esta relación se ha puesto en la doctrina italiana, la cual resalta la sinergia a que lleva el empleo conjunto de ambos conceptos. Sobre el particular, Vid. Criscuoli, Giovanni, Ragionevolezza e buona fede, en Rivista di Diritto Civile (1984), 1, pp. 709 ss.; Troiano, Stefano, cit. (n. 3), pp. 369 ss.; Piraino, Fabrizio, Diligenza, buona fede e ragionevolezza nelle pratiche commerciali scorrette. Ipotesi sulla ragionevolezza nel diritto privato, en Europa e Diritto Privato (2010), 4, pp. 1117-1194; Navarretta, Emmanuela, Buona fede e ragionevolezza nel diritto contrattuale europeo, en Europa e Diritto Privato (2012), 4, pp. 953-980; Piraino, 
la doctrina nacional no ha prestado mayor atención a esta relación, resulta destacable que para algunos autores los deberes emanados de la buena fe han de ser modelados según lo que resulta razonablemente exigible ${ }^{53}$. Así, por ejemplo, en lo que se refiere a deberes de información derivados de la buena fe, se afirma que tales deberes comprenden lo que los contratantes razonablemente pueden esperar de la contraparte, pues lo que se protege son las expectativas razo nables ${ }^{54}$. A su vez, se ha afirmado que la noción objetiva de buena fe impone la necesidad de establecer la conducta socialmente exigible de acuerdo con el modelo del "hombre razonable". En este sentido, afirma López Santa María: "la buena fe objetiva se aprecia en abstracto, prescindiendo el juez de las persuasiones, creencias o intenciones psicológicas de los contratantes, para puntualizar, él, la conducta socialmente exigible de las partes, exclusivamente en base a la equidad, a los usos y, en general, como habría dicho Savigny, al espíritu del pueblo o al modelo del hombre razonable" ${ }^{55}$. La opinión de este autor ha sido en más de una ocasión textualmente seguida en la jurisprudencia ${ }^{56}$.

\section{LA RAZONABILIDAD COMO INSTRUMENTO PARA SOSLAYAR LA INCERTIDUMBRE}

El tercer grupo de casos en que se puede observar el uso de la razonabilidad como criterio decisorio dice relación con la toma de decisiones en condiciones de incertidumbre. Se trata de situaciones en que, por aplicación del non liquet, el juez debe tomar una decisión, pero sin tener la certeza absoluta respecto de la situación a decidir. Sin perjuicio de otros que puedan identificarse, en esta situación se encuentran: (i) la indemnización del lucro cesante, (ii) el establecimiento del nexo de causalidad material, en algunos casos; y (iii) la determinación del daño contingente.

\section{La razonabilidad en la indemnización del lucro cesante y del daño futuro}

En Chile, entre las partidas indemnizatorias más conflictivas se encuen-

Fabrizio, Buona fede, ragionevolezza e «efficacia immediata» dei principî (Nápoles, Edizioni Scientifiche Italiane, 2017).

${ }^{53}$ Así Segura Riveiro, Francisco, cit. (n. 51), pp. 499 ss.

${ }^{54}$ Vid. De la Maza, Íñigo, Buena fe, el reverso de la moneda. A propósito del dolo por omisión y el deber precontractual de informar, en Revista Chilena de Derecho Privado, 11 (2008), p. 52.

${ }^{55}$ Cfr. López Santa María, Jorge, Los contratos parte general (4a edición, Santiago, Editorial Jurídica de Chile, 2005), II, p. 402.

${ }^{56}$ Vid. Corte Suprema, 29 de diciembre de 2011, Rol No 1872-2010; Corte Suprema, 2 de septiembre de 2014, Rol No 14243-2013; Corte Suprema de 2 de marzo de 2017, Rol No 1573-2016. 
tran el lucro cesante y el daño futuro, pues, por aplicación del requisito de certidumbre, los jueces terminan frecuentemente negando esta indemnización. En efecto, atendido que tanto el lucro cesante como el daño futuro son por definición daños hipotéticos, que carecen de absoluta certeza ${ }^{57}$, es simplemente imposible demostrar a ciencia cierta su ocurrencia. En los últimos años, sin embargo, el recurso a las ideas de normalidad y de razonabilidad ha permitido enfrentar este problema ${ }^{58}$. En este sentido, se ha dicho que "si se trata de un daño futuro que con probabilidad cercana a la certeza va a ocurrir, la víctima no necesita esperar que se materialice y puede demandar su reparación anticipada, porque se trata de un daño suficientemente cierto. Lo que ocurrirá en el futuro rara vez tiene una certidumbre matemática, por lo que el derecho se contenta con un grado de certeza razonable: se exige que el daño futuro sea la prolongación natural de un estado actual de cosas. Esto ocurre frecuentemente con los gastos futuros que provoca un daño corporal (daño emergente por gastos de hospitalización o de renovación de una prótesis, por ejemplo); pero, sobre todo, sucede con el lucro cesante, donde la pérdida de beneficios futuros se calcula proyectando, sobre la base de una probabilidad razonable, la situación que hubiere debido tener la víctima de no haber ocurrido el accidente" 59 . En sentido semejante se ha dicho que la única forma de lograr la indemnización del lucro cesante es moderar el requisito de certidumbre, en consecuencia, "ha de pedirse, pues, un razonable grado de certeza, equivalente e una sólida probabilidad, que se traduce en una composición de los extremos y que se reflejará en la prueba"60.

En consonancia con tal doctrina, se ha consolidado en la jurisprudencia la idea de que corresponde indemnizar el lucro cesante cuando, de acuerdo con un criterio de normalidad del curso de los acontecimientos, existan razonables probabilidades de que la ganancia alegada efectivamente se hubiera obtenido. En tal sentido, en fallo confirmado por la Corte Suprema $^{61}$, la Corte de Santiago sostuvo que, del intrínseco componente de eventualidad del lucro cesante se deriva "que en esta clase de daños no pueda

${ }^{57}$ De último sobre el carácter hipotético del lucro cesante, Vid. PeÑaIlillo Arévalo, Daniel, Sobre el lucro cesante, en Revista de Derecho Universidad de Concepción 243 (2018), p. 11 ss.

${ }^{58}$ En un sentido equivalente a lo expuesto, también se ha dicho que "el requisito de certidumbre del daño resarcible debe ser moderado en materia de lucro cesante, puesto que su intrínseco componente de eventualidad -se trata de ganancias esperadas- así lo exige". Cfr. Corte de Apelaciones de Santiago, 16 de abril de 2014, Rol No 3509-2013 (énfasis añadido).

${ }^{59}$ Cfr. Barros, Enrique, cit. (n. 28), p. 237.

${ }^{60}$ Cfr. Peñailillo, Daniel, cit. (n. 57), p. 12.

${ }^{61}$ Corte Suprema, 15 de octubre de 2014, Rol No 23.116-2014. 
requerirse el mismo nivel de certidumbre que es dable reclamar en materia de daño emergente. Es por ello que en materia de lucro cesante se busque, más que una certeza, una probabilidad razonable de utilidades futuras, proyectada sólo conforme al curso normal de los acontecimientos' ${ }^{2} 2$. Asimismo, la Corte Suprema ha afirmado que "la determinación del lucro cesante supone un examen de razonabilidad y probabilidad cierta de ocurrencia"r3.

En síntesis, el criterio de las probabilidades razonables permite lidiar con el carácter intrínsecamente hipotético o eventual del lucro cesante, otorgando un parámetro para establecer la certeza del mismo, lo que, a su vez, posibilita la dictación de una sentencia fundada, ya sea acogiendo o denegando la indemnización solicitada ${ }^{64}$.

\section{La razonabilidad en el establecimiento del nexo de causalidad material}

El establecimiento de nexo de causalidad material usualmente no da mayores complicaciones, pues, sin perjuicio de lo que jurídicamente se decida respecto de la responsabilidad, aparece claro que sin la actividad del demandado el daño no se hubiera producido; sin embargo, existe una serie de casos en que dicho establecimiento se dificulta, en consideración a que se desconoce si efectivamente el sujeto demandado ha tenido participación en el hecho lesivo, o bien, si el daño es efectivamente una consecuencia de su actuar ilícito. Con el fin de resolver tales casos, se ha empleado el

${ }^{62}$ Cfr. Corte de Apelaciones de Santiago, 16 de abril de 2014, Rol No 35092013.

${ }^{63}$ Cfr. Corte Suprema, 11 de mayo de 2015, Rol No 24212-2014. En el mismo, sentido ha dicho que "para la reparación del lucro cesante no se exige certeza en la determinación de la pérdida patrimonial -como propone el recurrente-, sino un juicio de probabilidad razonable en base a los antecedentes aportados por la víctima”. Cfr. Corte Suprema, 14 de diciembre de 2015, Rol No 15761-2015.

${ }^{64}$ Además de las sentencias citadas en la nota precedente, con un resultado favorable al recurrente, $v$. gr. Vid. Corte Suprema, 28 de septiembre de 2016, Rol No 7237-2015; Corte Suprema, 16 de abril de 2018, Rol No 10372-2017; Corte Suprema, 5 de marzo de 2018, Rol No 82482-2016. También es posible observar casos en que el recurrente invoca el estándar de razonabilidad como umbral para determinar la certeza del lucro cesante, pero su alegato no es acogido por la Corte Suprema, en razón de que se trata de alterar los hechos establecidos en la instancia, con todo, estos casos resultan relevantes, pues el máximo tribunal no niega, ni siquiera pone en duda, el hecho de que la probabilidad razonable es efectivamente el criterio que sirve para determinar la certeza del lucro cesante, en tal sentido, $v$. gr. vid. Corte Suprema, 28 de abril de 2004, Rol No 965-2003; Corte Suprema, 12 de agosto de 2008, Rol No 2555-2008; Corte Suprema, 9 de septiembre de 2014, Rol No 16582-2014; Corte Suprema, 22 de julio de 2015, Rol No 30182-2014; Corte Suprema, 18 de enero de 2016, Rol No 7001-2015; Corte Suprema, 16 de abril de 2018, Rol No 10372-2017. 
criterio de razonabilidad en dos sentidos, en primer lugar, para establecer una suerte de presunción del nexo causal y, en segundo lugar, para establecer el nexo causal a través de un juicio de probabilidades razonables.

En el primer sentido, a modo de ejemplo, puede citarse la sentencia de 18 de diciembre de 2013, dictada a propósito de la demanda intentado contra el Fisco de Chile por la muerte de una persona en el tsunami del 2010. Los demandantes alegaban que la muerte se habría producido porque el occiso y su familia habían escuchado el mensaje radial en que el intendente regional descartaba la ocurrencia de un tsunami, lo cual los llevó a permanecer en su casa y ser luego alcanzados por la ola. Dado que los demandantes no tenían forma de acreditar que efectivamente habían escuchado el mensaje radial, la demanda fue desechada en primera y segunda instancia, pues, al no estar comprobado que efectivamente habían escuchado la trasmisión radial, no estaba probado el nexo causal. En síntesis, la Corte Suprema, conociendo del recurso de casación, sostuvo que las pruebas allegadas al proceso hacían razonablemente plausible los alegatos de la familia y, dictando sentencia de reemplazo, acoge la demanda.

El segundo sentido se ha afirmado que, a diferencia de la responsabilidad penal en que el estándar de convicción es más elevado, en la responsabilidad civil bastan las probabilidades razonables para arribar a una condena ${ }^{65}$.

\section{La razonabilidad como criterio para identificar al daño contingente}

El Código Civil chileno contiene una interesante -aunque poco utilizada- norma relativa a la función preventiva de la responsabilidad civil, esto es, el artículo 2333 tocante al daño contingente ${ }^{66}$. Ahora bien, para establecer cuándo se está en presencia de esta hipótesis de daño, cuya principal característica es que no ha ocurrido, sino que constituye una a menaza de daño, un daño temido, también se recurre a la idea de razonabilidad, en este sentido se afirma que el daño contingente se caracteriza porque aún no se ha generado la lesión "sino que presenta una probabilidad razo-

${ }^{65}$ Vid. Corte Suprema, 24 de junio de 2015, Rol No 32830-2014.

${ }^{66}$ Sobre esta institución pueden verse los acuciosos estudios de Díez Schwerter, a saber: Díez Schwerter, José Luis - Delgado Schneider, Verónica, Algunas útiles herramientas olvidadas en nuestra práctica del Derecho de Daños, en Revista de Derecho Universidad de Concepción 214 (2003); Díez Schwerter, José Luis, Notas sobre la acción preventiva de daños del artículo 2333 del Código Civil, en Revista de Derecho Universidad de Concepción 217-218 (2005); Díez Schwerter, José Luis, La acción de dañó contingente del artículo 233 del Código Civil: sus elementos y ámbito de aplicación, en Revista de Derecho Pontificia Universidad Católica de Valparaíso 46 (2016); Díez Schwerter, José Luis, La aplicación de la acción por daño contingente en Chile, Colombia y Ecuador: del modelo de Bello a nuestros dias, en Revista de Derecho Privado de la Universidad Externado 30 (2016). 


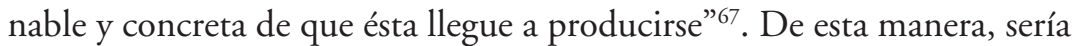
posible definir el daño contingente como "aquel respecto del cual existen razonables probabilidades de ocurrencia, si no se remueve la fuente de peligro". Así las cosas, al igual que en los casos recientemente citados, la razonabilidad es utilizada para soslayar la incertidumbre que significa el no poder establecer a ciencia cierta si el daño efectivamente se producirá.

\section{OBSERVACIONES FINALES}

Al finalizar esta breve revisión, cabe señalar que la noción de lo razonable o razonabilidad, presente en el Código Civil desde su versión original, ha encontrado aplicaciones recientes, principalmente doctrinarias, pero también jurisprudenciales, en diversos ámbitos del Derecho Privado nacional. En particular, cabe destacar el frecuente uso del adjetivo razonable, así como del adverbio razonablemente, por parte de la jurisprudencia y doctrina, lo que se puede comprobar fácilmente introduciendo la raíz "razonab" en alguna base de datos jurídica. Sin embargo, a diferencia de lo que ha ocurrido en otras latitudes, como en Italia, por ejemplo, no encontramos un estudio acabado del alcance e implicancias del empleo de la razonabilidad como criterio decisorio en el Derecho privado y muchas veces se acude a ella como algo autoevidente, en circunstancias que no necesariamente es así.

En particular, los usos identificados en este trabajo dicen relación con: (i) la razonabilidad como parámetro de tiempo, calidad e idoneidad; (ii) la razonabilidad como sinónimo de sensatez, con especial referencia al paradigma de la persona razonable; y (iii) la razonabilidad como instrumento para soslayar la incertidumbre, permitiendo al juez dictar sentencia en casos en que no es posible alcanzar una total certeza, sino solamente una certeza o probabilidad razonable.

Al margen de lo anterior, llama la atención el hecho de que no hayamos encontrado casos en que se haya acudido a la razonabilidad en una de sus aplicaciones más difundidas, esto es, la razonabilidad como criterio hermenéutico, específicamente como criterio de interpretación del con-

${ }^{67}$ Rodríguez Grez, Pablo, Responsabilidad extracontractual (Santiago, Editorial Jurídica de Chile, 1999), pp. 284 ss. En el mismo sentido Pino Silva, Néstor A., La responsabilidad preventiva, en Ius Novum 2 (2009), p. 247, quien afirma que el daño contingente se distingue del daño eventual por el hecho de que "respecto del daño eventual no existe la convicción razonable de qué sucederá y en el contingente sí la hay". La misma idea, siguiendo también a Rodríguez, se desprende de Molinari Valdés, Aldo, De la responsabilidad civil al derecho de daños y tutela preventiva civil, (Santiago, LexisNexis, 2004), pp. 204 ss. 
trato $^{68}$. En efecto, atendido que la común intención de los contratantes es algo prácticamente imposible de establecer en la inmensa mayoría de los casos, una solución ha sido establecer que el contrato debe ser interpretado según lo que personas razonables, puestas en las mismas condiciones y circunstancias, habrían acordado ${ }^{69}$. De esta manera, la razonabilidad permite adoptar una decisión fundada, dotando de contenido preciso a las cláusulas contractuales en disputa, a pesar de la incertidumbre sobre la real intención de quienes las contrajeron. Una posible explicación para esta ausencia es el hecho de que en la práctica los mismos resultados a que se llega mediante la razonabilidad pueden ser alcanzados recurriendo a la buena $\mathrm{fe}^{70}$, aunque también podría ser el hecho de que todavía existe un apego a la intención de los contratantes y no resulta simple sostener que se abandonará la búsqueda de dicha intención para establecer lo que sería razonable atendidas las circunstancias.

${ }^{68}$ Vid. Principios Unidroit, art. 4.1 inc. $2^{\circ}$; CISG, art. 8, inc. 2o; PECL, art. 5:101.

${ }^{69}$ Con todo, cabe señalar que en una perspectiva semejante la razonabilidad es aludida con referencia al propósito práctico perseguido con la celebración del contrato (que generalmente conllevará un ejercicio de interpretación), el cual se juzga según lo que es razonable esperar. Vid. Mejías Alonzo, Claudia, El incumplimiento contractual y sus modalidades, en GuzMán Brito, Alejandro (editor), Estudios de Derecho Civil III (Santiago: LegalPublishing, 2008), pp. 459 ss.

${ }^{70}$ Así parecieron entenderlo los redactores de los PLDC, en los cuales como norma de clausura en lo que a interpretación se refiere no se alude a la razonabilidad, sino a la buena fe, Vid. PLDC, artículos 73 y 75 . Sobre las disquisiciones que presenta la buena fe versus la razonabilidad como criterios de interpretación, Vid. Viglione, Filippo, Good Faith and Reasonableness in Contract Interpretation: a Comparative Perspective, en European Business Law Review (2009), pp. 835 ss. 


\section{BiBLIOGRAFÍA}

Abusleme Salah, María Agnes, Las doctrinas de los actos propios y de la protección a la apariencia: una mirada comparativa, en Revista del Magister y Doctorado en Derecho de la Universidad de Chile 2 (2008).

BANFi del Río, Cristián, Por una reparación integral del daño extracontractual limitada a los hechos dolosos o gravemente negligentes, en Ius et Praxis 18 (2012), 2.

Barcellona, Mario, Clausole generali e giustizia contrattuale. Equità e buona fede tra Codice civile e diritto europeo (Turín, Giappichelli, 2006).

Barros Bourie, Enrique, Tratado de responsabilidad extracontractual (Santiago, Editorial Jurídica de Chile, 2006).

BAZÁN L., José Luis - MADRID R., Raúl, Razonabilidad y racionalidad en el derecho, en Revista Chilena de Derecho 18 (1991), 2.

Carnevali Rodríguez, Raúl - Castillo Val, Ignacio, El estándar de convicción de la duda razonable en el proceso penal chileno, en particular la relevancia del voto disidente, en Ius et Praxis 17 (2011), 2.

CARRASCO QUIROGa, Edesio, Razonabilidad y proporcionalidad: criterios para la determinación de la consulta indigena en proyectos de inversión en el marco del convenio No 169 de la OIT, en Revista Chilena de Derecho 40 (2013), 1.

Celedón Förster, Rosario - Silberman Veszpremi, Patricia, Responsabilidad precontractual por ruptura de negociaciones contractuales (Santiago, Editorial Jurídica de Chile, 2010).

CONTARDo GonZÁlez, Juan Ignacio, El derecho del deudor a la subsanación o corrección del cumplimiento no conforme [right to cure]. Acercamiento desde los instrumentos de derecho contractual uniforme hacia el derecho chileno de contratos, en Ius et Praxis 23 (2017), 1.

Cordero Vega, Luis, La responsabilidad por falta de servicio y la jurisprudencia de la Corte Suprema, en Letelier WarTenberg, Raúl (coordinador), La falta de servicio (Santiago, Thomson Reuters, 2012).

Corral Talciani, Hernán, Lecciones de responsabilidad extracontractual (2a edición, Santiago, Thomson Reuters, 2013).

Criscuoli, Giovanni, Ragionevolezza e buona fede, en Rivista di Diritto Civile (1984), 1.

De Ávila Martel, Alamiro, La filosofía jurídica de Andrés Bello, en AA.VV., Congreso Internacional Andrés Bello y el Derecho (Santiago, Editorial Jurídica de Chile, 1982).

De la Maza Gazmuri, Ínigo, Comentarios de jurisprudencia. Contratos especiales, en Revista Chilena de Derecho Privado 15 (2010).

De la Maza Gazmuri, Ínigo, Contratos por adhesión. Una mirada al caso estadounidense, en Revista Chilena de Derecho Privado 5 (2005).

De la Maza Gazmuri, Íñigo, Información y expectativas razonables, en El Mercurio Legal, viernes 05 de enero de 2018, disponible [en línea]: http://www.elmercurio. com/Legal/Noticias/Analisis-Juridico/2018/01/05/Informacion-y-expectativasrazonables.aspx, consultado 15 de ene. de 18.

De la Maza Gazmuri, Íñigo, La distribución del riesgo y la buena fe. A propósito del error, el dolo y los deberes precontractuales de información, en Revista de Derecho Pontificia Universidad Católica de Valparaíso 37 (2011).

De la MAZA, Íñigo, Buena fe, el reverso de la moneda. A propósito del dolo por omisión y el deber precontractual de informar, en Revista Chilena de Derecho Privado 11 (2008).

Díez Schwerter, José Luis - Delgado Schneider, Verónica, Algunas útiles herra- 
mientas olvidadas en nuestra práctica del Derecho de Daños, en Revista de Derecho Universidad de Concepción 214 (2003).

Díez Schwerter, José Luis, La acción de dañó contingente del artículo 233 del Código Civil: sus elementos y ámbito de aplicación, en Revista de Derecho Pontificia Universidad Católica de Valparaíso 46 (2016).

Díez Schwerter, José Luis, La aplicación de la acción por daño contingente en Chile, Colombia y Ecuador: del modelo de Bello a nuestros días, en Revista de Derecho Privado de la Universidad Externado 30 (2016).

Díez SCHWERTER, José Luis, Notas sobre la acción preventiva de daños del artículo 2333 del Código Civil, en Revista de Derecho Universidad de Concepción 217-218 (2005).

EKDAHL Escobar, María Fernanda, La doctrina de los actos propios: el deber jurídico de no contrariar conductas propias pasadas (Santiago, Editorial Jurídica de Chile, 1989).

Fabiani, Ernesto, Clausola generale, en Enciclopedia del diritto. Annali (vol. V, Milán, Giuffrè, 2012).

Finsterbusch Romero, Christian, La extensión de los ajustes razonables en el derecho de las personas en situación de discapacidad de acuerdo al enfoque social de derechos humanos, en Ius et Praxis 22 (2016).

Gandarillas Serani, Cristián, Algunas consideraciones acerca del deber de mitigación o minimización del daño frente al incumplimiento contractual, en PIZARro WiLSON, Carlos (coordinador), Estudios de Derecho Civil IV (Santiago, LegalPublishing, 2009).

GiorginI, Erika, Ragionevolezza e autonomia negoziale (Nápoles, Edizioni Scientifiche Italiane, 2010).

Huepe Ártigas, Fabián, Discrecionalidad administrativa y razonabilidad (Santiago, Thomson Reuters, 2018).

JaKsIC, Ivan, Andrés Bello, la pasión por el orden (Santiago, Editorial Universitaria, 2001).

López DíAz, Patricia Verónica, La indemnización compensatoria por incumplimiento de los contratos bilaterales como remedio autónomo en el derecho civil chileno, en Revista chilena de derecho privado 15 (2010).

López Díaz, Patricia, Los supuestos y el alcance de la indemnización de daños como medio de tutela precontractual en el Código Civil chileno y su eventual confluencia con la indemnización por incumplimiento contractual, en Revista Ius et Praxis 24 (2018), 1.

López SANTA María, Jorge, Los contratos parte general (4a edición, Santiago, Editorial Jurídica de Chile, 2005).

MarTíneZ, José Ignacio - ZúNIIga Urbina, Francisco, El principio de razonabilidad en la jurisprudencia del Tribunal Constitucional, en Estudios Constitucionales (2011), 1.

Mejías Alonzo, Claudia, El incumplimiento contractual y sus modalidades, en GuZMÁN Brito, Alejandro (editor), Estudios de Derecho Civil III (Santiago, LegalPublishing, 2008).

Mejías Alonzo, Claudia, El incumplimiento resolutorio en el Código Civil (Santiago, AbeledoPerrot, 2011).

Mejías Alonzo, Claudia, La excepción de contrato no cumplido, un análisis de su aplicación en la jurisprudencia nacional reciente y en la doctrina, en Revista de Derecho Universidad Católica del Norte 21 (2014), 1.

Molinari Valdés, Aldo, De la responsabilidad civil al derecho de daños y tutela preventiva civil (Santiago, LexisNexis, 2004). 
NaVArRetTa, Emmanuela, Buona fede e ragionevolezza nel diritto contrattuale europeo, en Europa e Diritto Privato (2012), 4.

Nicolau, Noemí Lidia, El principio de razonabilidad en el Derecho Privado en Revista de Derecho Privado 1 (2010).

PAтTi, Salvatore, Ragionevolezza e clausole generali (2a edición, Milán, Giuffrè, 2016).

Peñailillo Arévalo, Daniel, Sobre el lucro cesante, en Revista de Derecho Universidad de Concepción 243 (2018).

Perlingieri, Giovanni, Profili applicativi della ragionevolezza nel diritto civile (Nápoles, Edizioni Scientifiche Italiane, 2015).

Pino Silva, Néstor A., La responsabilidad preventiva, en Ius Novum 2 (2009).

Pinochet Olave, Ruperto, La protección del contratante débil: doctrina de las expectativas razonables, en Gaceta Jurídica 297 (2005).

Piraino, Fabrizio, Buona fede, ragionevolezza e "efficacia immediata" dei principî (Nápoles, Edizioni Scientifiche Italiane, 2017).

PIRAINo, Fabrizio, Diligenza, buona fede e ragionevolezza nelle pratiche commerciali scorrette. Ipotesi sulla ragionevolezza nel diritto privato, en Europa e Diritto Privato (2010), 4.

Pizarro W., Carlos - Bahamondes O., Claudia, La exposición de la víctima al daño: desde la culpabilidad a la causalidad, en Revista de Derecho de la Pontificia Universidad Católica de Valparaiso 39 (2012).

Pizarro Wilson, Carlos, Contra la fatalidad del perjuicio. A propósito del deber de mitigar el daño, en Revista de Derecho de la Pontificia Universidad Católica de Valparaiso 41 (2013).

PiZARRo Wilson, Carlos, Daños en la construcción, fuerza mayor y terremotos, en Revista de Derecho de la Pontificia Universidad Católica de Valparaiso 34 (2010).

Prado López, Pamela, La colaboración del acreedor en los contratos civiles (Santiago, Thomson Reuters, 2015).

RICCI, Annarita, Il criterio della ragionevolezza nel diritto privato (Padova, CEDAM, 2007).

Rodríguez Grez, Pablo, Responsabilidad extracontractual (Santiago, Editorial Jurídica de Chile, 1999).

San Martín Neira, Lilian C., El pago al poseedor del crédito. Un caso de apariencia culposa", en Domínguez Hidalgo, Carmen et al. (coordinadores), Estudio de Derecho Civil VIII (Santiago, Thomson Reuters, 2013).

San Martín Neira, Lilian C., La carga del perjudicado de evitar o mitigar el daño (Bogotá, Universidad Externado de Colombia, 2012).

San Martín Neira, Lilian C., El criterio de "lo razonable". Una herramienta para delimitar la carga del perjudicado de evitar o mitigar el daño, en Derecho y Justicia 1 (2011), disponible [en línea]: http://www.derecho-ucsh.cl/categoria/revista/ (consultado 17 de enero de 2018).

Segura Riveiro, Francisco, Buena fe, un aspecto de tensión entre los sistemas jurídicos, en Departamento de Derecho Privado Universidad de Concepción (coordinador), Estudios de Derecho Civil V(2010).

TAPIA R., Mauricio, Caso fortuito en el Derecho chileno (Santiago, LegalPublishing, 2013).

TOMÁs MarTínez, Gema, La influencia internacional en la creciente presencia del estándar de la razonabilidad en el derecho privado, en Murillo VILLAR, Alfonso et alt., Homenaje al Profesor Armando Torrent (Madrid, Dikynson, 2016). 
TOMÁs MARTínez, Gema, La sustitución del "buen padre de familia” por el estándar de la "persona razonable": reforma en Francia y valoración de su alcance, en Revista de Derecho Civil 2 (2015), 1, disponible [en línea]: http://www.nreg.es/ojs/index. $\mathrm{php} / \mathrm{RDC} /$ issue/view/18/showToc (consultado el 15 de enero de 2018).

Troiano, Stefano, La "ragionevolezza" nel diritto dei contratti (Padova, CEDAM, 2005).

Troiano, Stefano, Ragionevolezza, en Enciclopedia del diritto. Annali VI (Milán, Giuffrè, 2013).

Vidal O., Álvaro - Momberg U., Rodrigo (coordinadores), Cumplimiento específico y ejecución forzada del contrato (Valparaíso, Ediciones Universitarias de Valparaíso, 2018).

VIDAL Olivares, Álvaro, La carga de mitigar las pérdidas del acreedor y su incidencia en el sistema de remedios por incumplimiento, en GUZMÁN BRITO, Alejandro (editor), Estudios de Derecho Civil III (Santiago, LegalPublishing, 2008)

VIDAL Olivares, Álvaro, La pretensión de cumplimiento específico de las obligaciones no dinerarias y los costes excesivos para el deudor como límite a su ejercicio, en VIDAL O., Álvaro - Momberg U., Rodrigo (editores), Cumplimiento especifico y ejecución forzada del contrato (Valparaíso, Ediciones Universitarias de Valparaíso, 2018).

Viglione, Filippo, Good Faith and Reasonableness in Contract Interpretation: a Comparative Perspective, en European Business Law Review (2009).

Zorzetto, Silvia, Ragionevolezza, politica del diritto e semiotica giuridica. Considerazioni in margine al libro Ragionevolezza e autonomia negoziale, en Diritto \& Questioni Pubbliche 10 (2010), disponible [en línea]: http://www.dirittoequestionipubbliche. org/ (consultado 15 de enero de 2018). 